\title{
A New Disease in Limonium hybrids. I. Molecular Identification
}

\author{
A. Gera, ${ }^{1}$ L. Maslenin, and A. Rosner \\ Department of Virology, Agricultural Research Organization, The Volcani \\ Center, Bet Dagan 52050, Israel
}

M. Zeidan

The Plant Protection and Inspection Services, Ministry of Agriculture, Bet Dagan 50250, Israel

\section{S. Pivonia}

Northern Arava Research and Development, Sapir, D.N. Arava 86825, Israel

\section{P.G. Weintraub}

Department of Entomology, ARO, Gilat Research Center, D.N. Negev 85280, Israel

Additional index words. polymerase chain reaction, elm yellows, almond witches broom, phytoplasma, Limonium latifolium

\begin{abstract}
Yellows diseases in ornamental crops have become more common in Israel, and phytoplasmas have been detected in several crops. Recently, symptoms typical of a phytoplasma infection were observed on a large number of Limonium hybrids grown in commercial fields in Israel. Examination of samples from diseased plants by electron microscopy revealed the presence of pleiomorphic membrane-bound bodies in the phloem cells. Diseased plants were additionally analyzed by PCR using universal and nested primers and revealed upon sequencing products of 1143, 788 and 722 bp (Li-IL, Li-b2-IL, Li-v3-IL, respectively). Analysis of the PCR products, associated with infected Limonium, clustered within two major groups of phytoplasmas (16SrV and 16SrIX), elm yellows and almond witches broom. This is the first published record of these phytoplasmas in Israel.
\end{abstract}

Although many species of Limonium (Plumbaginaceae Juss.), herbaceous perennials, are native to the Mediterranean region, seedlings for commercial production are usually imported from Europe, North America or Asia. Two species and two hybrids are grown in commercial production in the Arava valley (located between the Dead Sea and Red Sea); these include Limonium altaica ('Emile'), $L$. sinuatum (annual statice), L. latifolium $\times L$. caspium ('Beltlaard'), and L. latifolium $\times$ L. bellidifolium ('Misty', 'Supreme' and 'Sunglow'). In any one year there are a total of $\approx 70 \mathrm{ha}$; $\approx 15$ ha are in L. sinuatum production and the remainder in L. altaica and Limonium hybrids. These plants are grown primarily for export to Europe as cut flowers for floral arrangements. Flowers are grown for 1 to 10 years in tunnels $(7 \times 100 \mathrm{~m})$ covered with plastic; both ends are open and ventilation holes are cut about every 2 $\mathrm{m}$. For the first 15 years of commercial production in the Arava, the crops were not affected by yellows disease. In October 2000 diseased plants were first observed in the northern Arava.

Received for publication 23 June 2003 Accepted for publication $24 \mathrm{Jan} .2004$. Contribution from the Institute of Plant Protection, Agricultural Research Organization, The Volcani Center, Bet Dagan, Israel, No. 517/02. This research was supported in part by a grant from the Chief Scientist, Ministry of Agriculture, State of Israel.

${ }^{1}$ Corresponding author; e-mail abedgera@ volcani. agri.gov.il.
Only L. latifolium hybrids were observed to be infected. Symptoms included: small and/or deformed/discolored flowers; small, narrow basal leaves, often yellow in color; excessive leaf growth (witches broom or 'asparagus fern'); and eventual plant death. Over the course of that season up to $60 \%$ of the plants were affected in some areas. Symptoms resembled those caused by phytoplasma infections.

The present paper reports the outbreak of phytoplasma in Limonium hybrids grown in commercial fields in Israel and the molecular identification and phylogenetic relationships of diverse phytoplasmas associated with the disease.

\section{Materials and Methods}

Mechanical inoculation. Leaf samples of Limonium grown in commercial plastic tunnels were examined for virus particles using electron microscopy and mechanical inoculation. Symptomatic samples were homogenized in $1 \% \mathrm{~K}_{2} \mathrm{HPO}_{4}$, and the sap was inoculated to Capsicum annum L., Chenopodium quinoa Willd., C. amaranticolor, Cucumis sativus, Cucurbita pepo, Datura stramonium, Gomphrena globosa, Lycopersicon esculentum, Nicotiana benthamiana Domin, N. clevelandii Glay, N. glutinosa, N. tabacum 'NN', N. tabacum 'Samsun', N. tabacum 'Samsun NN', $N$. tabacum Xanthi nc, N. rustica, N. sylvestis, N. tabacum 'White Burley', Petunia hybrida and Physalis floridensis Rybd., predusted with carborundum. These plants were maintained in the greenhouse for one month and observed for symptom development.

Electron microscopy. Crude plant extracts in $0.1 \mathrm{M}$ phosphate buffer were negatively stained with $20 \mathrm{~g} \cdot \mathrm{L}^{-1}$ uranyl acetate and examined for virus in a electron microscope (model 100CX II; Joel Ltd., Tokyo, Japan). For ultrathin sections, pieces of petioles and/or leaf veins ( 1 to $2 \mathrm{~mm}^{2}$ ) excised from healthy and symptomatic leaves of Limonium hybrids, were fixed in $2.5 \%$ glutaraldehyde buffered with $75 \mathrm{~mm}$ potassium phosphate, $\mathrm{pH} 7.0$, for $2 \mathrm{~h}$. The samples were then rinsed in the same buffer and postfixed in $1 \% \mathrm{OsO}_{4}$ for $3 \mathrm{~h}$. After a buffer rinse, the samples were dehydrated in a graded acetone series, embedded in an Epon-Araldite resin mixture, and polymerized as described by Orion and Franck (1990). Sectioned material was stained with uranyl acetate followed by lead nitrate and examined by electron microscopy.

Polymerase chain reaction and sequence analysis. DNA was prepared from leaf midribs and petioles as described by Tanne et al. (2000). DNA fragments were amplified using the universal phytoplasma primers P1/P7 (Schneider et al., 1993). The product was further amplified by nested PCR with the r16SF2/r16SR 2 and fU3-fR5 primer pairs (Lee et al., 1995). The DNA template in all PCR assays was $20 \mathrm{ng}$ in a $50 \mu \mathrm{L}$ assay. Standard PCR conditions were as in Tanne et al. (2000). Amplified samples were electrophoresed in a $1.2 \%$ agarose gel, stained with $0.5\left(\mathrm{~g} \cdot \mathrm{mL}^{-1}\right.$ ethidium bromide, and photographed under UV illumination (Sambrook et al., 1989). DNA extracted from symptom-free Limonium and naturally infected periwinkle plants served as negative and positive controls, respectively.

Amplified products from several Limonium samples were cleaned using QIAquick purification kit (Qiagen, Hildon, Germany) and sequenced by the dideoxynucleotide chain termination method, using r16SF2 or fU3 primers at the Weizmann Institute of Science, Rehovot, Israel. Sequence analysis was performed with the DNAMAN package, version 4 (Lynnon Biosoft, Canada). Phytoplasma-related sequences were initially identified using the BLASTN search program of the GenBank (Altschul et al., 1990). The nucleotide sequence of the phytoplasma infecting Limonium was compared to the following: almond witches' broom phytoplasma (AlmWB1-4, AF390136-9), american aster yellows phytoplasma (AAY, X68373), australian grapevine yellows phytoplasma (AUSGY, L76865), aster yellows phytoplasma (AY1, AF322645), aster yellows phytoplasma (SAY, AJ271323), Candidatus fraxini phytoplasma (AshY1, AF092209); Candidatus fraxini phytoplasma (AshY, X68339); Candidatus fraxini phytoplasma (AshY1-NY,AF092209); Candidatus fraxini phytoplasma (AshY3, AF105315); Candidatus fraxini phytoplasma (AshY5, AF105316); clover yellow edge phytoplasma (CYE-C,AF175304), clover yellow edge phytoplasma (CYE-Or, AF189288), Clover yellow edge phytoplasma (CYE-L, AF173558), elm yellows phytoplasma (EY- 

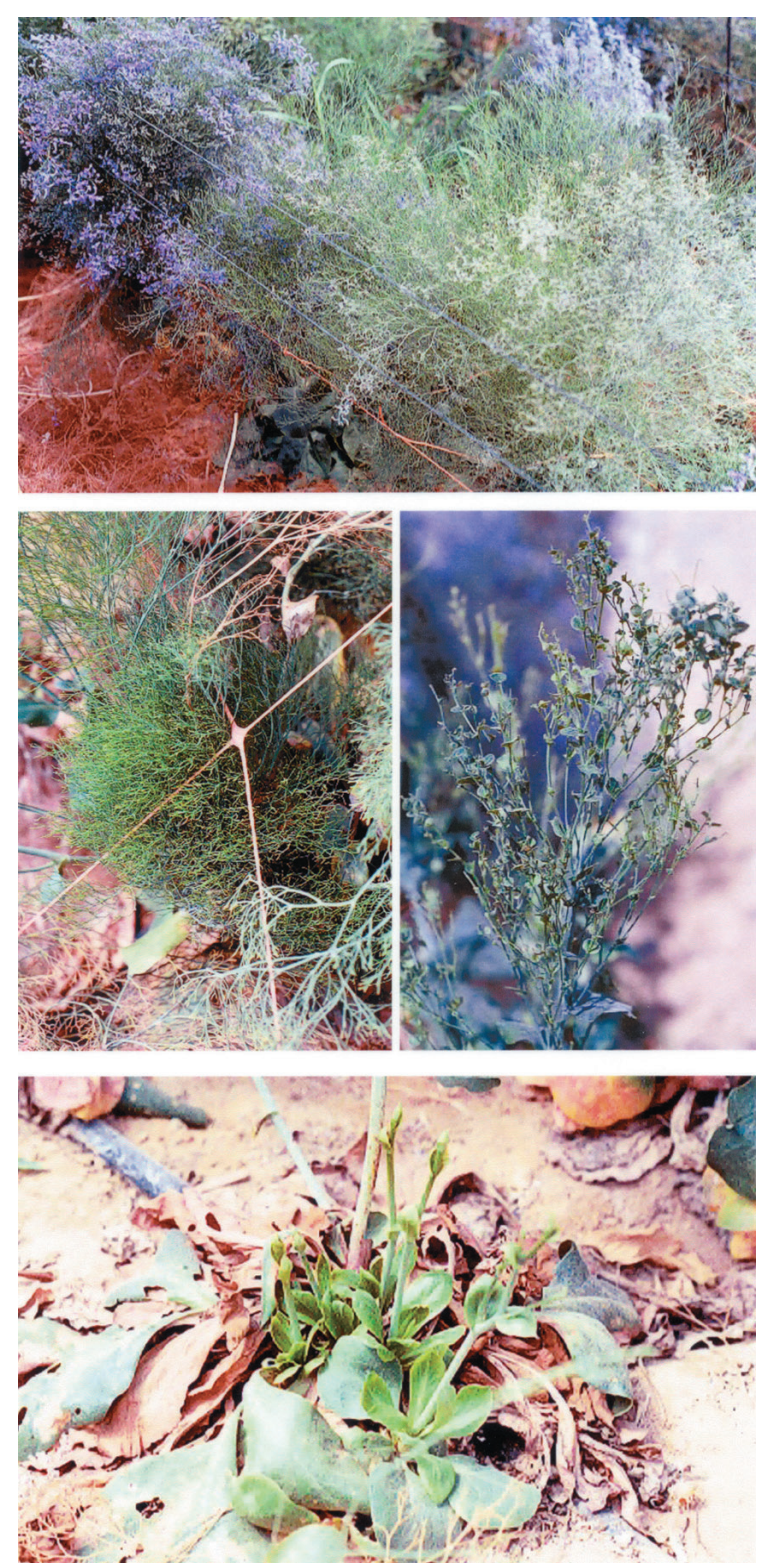

organism(PPER, X68374), mollicutes from $V$. myrtillus (VAC, X76430), mollicutes from $C$. roseus (STOL-Cros, X76427), mollicutes from $V$. vinifera (VK, X76428), phytoplasmasp.(LfY5, AF500334); Paulownia witches' broom phytoplasma (PauWB, AF279271 ), peanut witches' broom phytoplasma (PnWB, AY139868), rice yellow dwarf phytoplasma(RYD, AY139873), stolburphytoplasma (STOL-Lily, AY169309), stolbur phytoplasma (STOL,AF248959), sweetpotato witches' broom phytoplasma (SPWB, AY139866), Stylosanthes little leaf phytoplasma (SLI-AUS, AJ289192); tomato big bud phytoplasma (BB, AF222064), tsuwabuki witches broom phytoplasma (TWB, D12580),Ziziphus jujube witches broom phytoplasma (JWB-Ch, AF305240); Ziziphus jujube witches broom phytoplasma (JWB-Ko, AB052879); loofah witches-broom phytoplasma (LfWB1, AF353090); loofah witches-broom phytoplasma (LfWB2, AY139871); phytoplasma sp. LfY5-Oaxaca (LfY5, AF500333); western X phytoplasma (WX, L04682).

\section{Results}

A typical naturally infected Limonium is illustrated in Fig. 1. Symptoms included small and/or deformed or discolored flowers; small, narrow basal leaves, often yellow in color; excessive leaf growth (witches broom or asparagus fern). Over the course

Fig. 1. Symptoms of phytoplasma in naturally infected Limonium. (A) Healthy plant with blue flowers on left, diseased plant center right. (B) Asparagus fern. (C) Leaflets instead of flowers. (D) Narrow, yellow basal leaves developing above old broad healthy leaves.

Arl, AF268895); elm yellows phytoplasma (EY1-NY, AF189214); elm yellows phytoplasma(EY1-WVEY,AF122911); elm yellows phytoplasma (EY1-ULMUS, AF122910), elm yellows phytoplasma (ULW, X68376); mollicutes from Saccharum officinarum L. (SCWL, X76432), pigeon pea witches' broom phytoplasma (PPWB, AF248957); periwinkle little leaf phytoplasma (PLL-Bd, AF228053); brinjal little leaf phytoplasma (BLL-Bdbrinjal, AF228052); Candidatus mali phytoplasma (AT1, AJ542542), Candidatus pyri phytoplasma (PearD, U54989), Candidatus aurantifolia phytoplasma (WBDL, U15442), Candidatus phoenicium phytoplasma (CannPPH-21, AF515637), coconut lethal yellowing phytoplasma (LY-C2, AF498309); phytoplasma sp. (ACLR, X68338), mycoplasma-like of the season up to $60 \%$ of the plants were affected in some areas. None of the 20 herbaceous test plant species listed in the materials and methods exhibited any symptoms related to viral infection up to one month following mechanical inoculation.

Electron microscopy. Electron microscope (EM) observations of crude plant extracts revealed no virus or virus-like particles. EM of ultrathin sections of infected leaves of Limonium hybrids revealed the presence of pleiomorphic membrane-bound bodies (Fig. 2) in the phloem cells. The size ranged from 200 to $1000 \mathrm{~nm}$ in diameter. No other types of bodies were observed. Similar bodies were not observed in samples of healthy Limonium hybrid plants.

Polymerase chain reaction and sequence analysis. Amplification of phytoplasma related sequences using the universal primers P1/P7 followed by a nested PCR with internal primers indicated that all Limonium plants expressing symptoms were infected by phytoplasma, while symptom-less plants were phytoplasma-free (Fig. 3). The PCR fragments, 1143, 788 and 722 bp of several clones, designated Li-IL, Li-b2-IL, Li-v3-IL, respectively, were directly sequenced using r16SF2 or fU3 primers. Nucleotide sequencing of Li-IL amplified product have shown $99.4 \%$ identity with EY-Ar1,Li-b2IL product $83 \%$ identity with BLL-Bd-Brinjal and Li-V3-IL 91.4\% with PPWB phytoplasmas respectively. A comparison with 53 related sequences from the GenBank confirmed the classification of these phytoplasmas associated with Limonium disease to two major groups (16SrV and 16SrIX), elm yellows and almond witches' broom, respectively. Although, Li-IL and Li-b2-IL were classified to the same group they exhibit only $82.8 \%$ identity of nucleic acid sequence.

\section{Discussion}

A review of the literature revealed that phytoplasma infections are known from only a few species within the Plumbaginaceae: $L$. sinuatum in Korea (Hahm et al., 1998), Japan (Shiomi et al., 1999), Poland (Kaminska et al., 1999), and Lithuana (Valiunas et al., 2001), and Goniolimon tataricum (syns. Limonium tataricum) in Canada (Chang et al., 1996). Although L. sinuatum is grown in the same area of the Arava, and even immediately adjacent to L. latifolium, we have yet to find statice with symptoms of phytoplasmainfection. Limonium altaica also remains symptomless.

The symptoms in L. latifolium hybrids are typical of those of a phytoplasma infection, and sequence analysis of amplification products of 1143, 788 and 722 bp (Li-IL, Li-b2-IL, Li-v3IL, respectively) is consistent with elm yellows and almond witches' broom phytoplasmas classified into two major groups of $16 \mathrm{SrV}$ and 16SrIX according to Lee et al. (1998). These results emphasize that the use of molecular tools, especially sequencing amplified nucleic acid fragments of the 16SrRNA gene, provides tools to differentiate phytoplasmas that exist in mixed infection. These results show that

Fig. 2. Electron micrograph of a thin section through sieve cells of Limonium containing phytoplasmalike bodies indicated by arrows. Bar represents $200 \mathrm{~nm}$

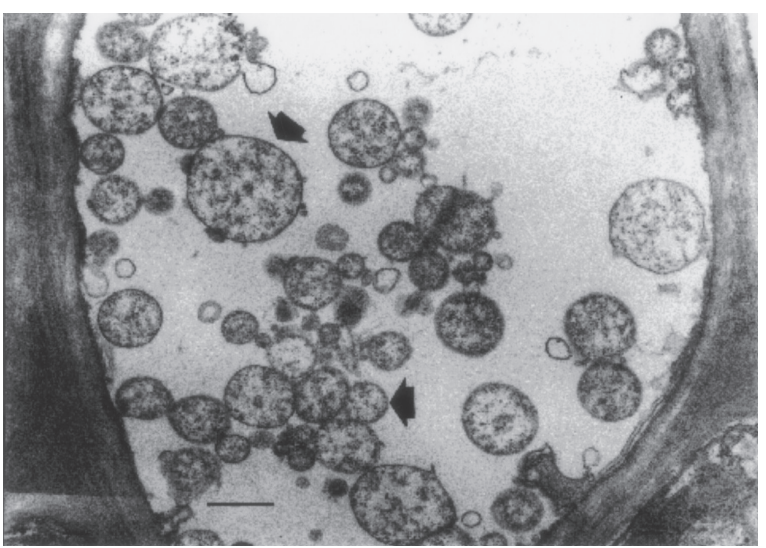


Fig. 3. Gel electrophoresis of products from polymerase chain reaction (PCR) performed on DNA extracted from Limonium using nested-PCR with primers $\mathrm{P} 1 / \mathrm{P} 7$ followed by primers r16SF2/r16SR2. Lane 1, DNA size markers, lane 2, healthy $L i$ monium, lane 3-5, symptomatic Limonium.
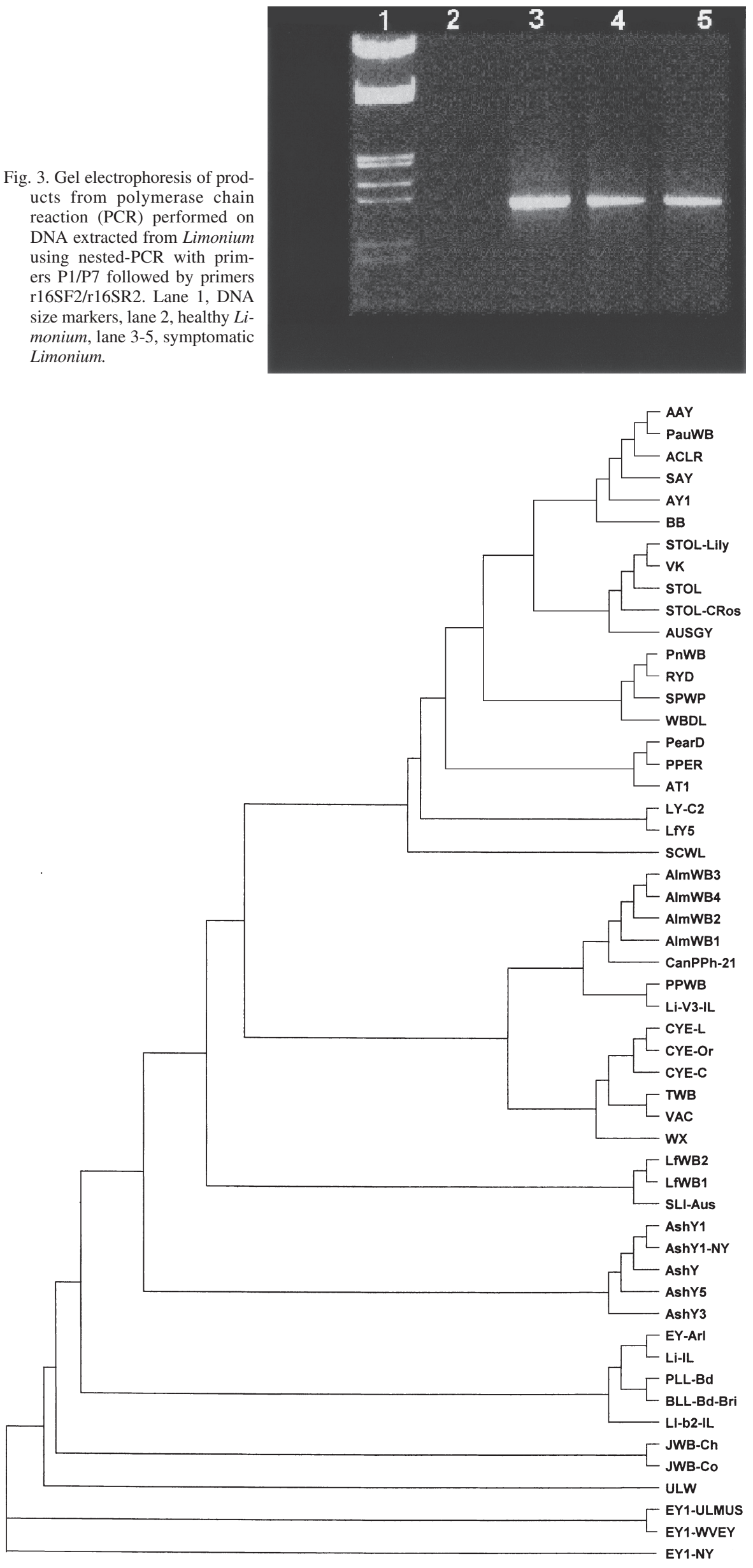

Fig 4. Relationship dendrogram of Limonium infecting phytoplasma $16 \mathrm{~s}$ rRNA fragment with related sequences of phytoplasmas. The nucleic acid sequence was compared first by a BLASTN search of GenBank. Tree descriptions were generated using the neighbor-joining algorithm and based on calculations from pairwise nucleotide sequence distances derived from the multiple alignment format (not shown). Horizontal scale indicates sequence divergence, and vertical scale is arbitrary. 
mixed phytoplasma infections associated with Limonium disease is not uncommon.

This is the first time an elm yellows disease and almond witches' broom have been recorded in Israel. Elm yellows phytoplasma has not been reported in Israel, but it has been present for years in North America (Baker, 1948), Europe (Maurer et al., 1993) and China (Griffiths et al., 1999). The disease was detected in a diverse group of woody or herbaceous plants: Eucalyptus (Marcone et al., 1996), Apocynum (Sunn hemp), Prunus (stone fruit), Rubus (raspberry, blackberry), Ulmus (elm), Vitis (grape), Ziziphus (jujube) (Griffiths et al., 1999), and, more recently, Parthenocissus quinquefolia (virginia creeper) (Harrison et al., 2001). However, almond witches' broom was recently detected in Lebanon (Abou-Jawdah, et al. 2002).

In 2000 growers in South America also observed a phytoplasma-type disease in 'Supreme' (L. latifolium $\times$ L. bellidifolium) plants grown in greenhouses. These seedlings, like those in Israel, were imported from California; most probably, this was the source of the phytoplasma. Phytoplasmas are vectored to plants by leafhoppers and planthoppers; in the following article we discuss the vectors found in Limonium.

\section{Literature Cited}

Abou-Jawdah, Y., A., Karakashian, H. Sobh, M Martini, and I. -M. Lee. 2002. An epidemic of almond witches'-broom in Lebanon: Classification and phylogenetic relationships of the associated phytoplasma. Plant Dis. 86:477-484.

Altschul, S.F., W. Gish, W. Miller, E.W. Myers, and D.J.Lipman. 1990. Basic local alignment search tool. J. Mol. Biol. 215:403-410.

Baker, W.L. 1948. Transmission by leafhoppers of the virus causing phloem necrosis of American elm. Science 108:307-308.

Chang, K.F., S.F. Hwang, and R.J. Howard. 1996. First report of a yellows disease of German statice (Goniolimon tataricum) in Canada caused by a phytoplasma. Canadian Plant Dis. Survey 76:15-20.

Griffiths, H.M.,W.A. Sinclair,E., Boudon-Padieu, X Daire, I.-M. Lee, A. Sfalanga, and A. Bertaccini. 1999. Phytoplasmas associated with elm yellows: molecular variability and differentiation from related organisms. Plant Dis. 83:1101-1104.

Hahm, Y.I., K. Min, J.S. Kim, H.W. Seo, and J.H Ahn. 1998. Surveys on disease occurrence in major horticultural crops in Kangwon alpine areas. Korean J. Plant Pathol. 14:668-675.

Harrison, N.A., H.M. Griffiths, M.L. Carpio, and P.A Richardson. 2001. Detection and characterization of an elm yellows (16SrV) group phytoplasma infecting Virginia creeper plants in southern Florida. Plant Dis. 85:1055-1062.

Kaminska, M., M. Korbin, and A. Rudzinska-Langwald. 1999. Occurrence and identification of aster yellows related phytoplasma in annual statice (Limonium sinuatum) in Poland. Phytopathol. Polonica 18:37-45.

Lee, I.-M., D.E. Gundersen, R.W. Hammond, and R.E. Davis. 1995. Use of mycoplasmalike organism (MLO) group-specific oligonucleotide primers for nested-PCR assays to detect mixed-MLO infections in a single host plant. Phytopathology 84:559-566.
Lee, I.-M., D.E. Gundersen-Rindal, R.E. Davis, and I.M. Bartoszyk. 1998. Revised classification scheme of phytoplasma based on RFLP analysis of $16 \mathrm{~S}$ rRNA and ribosomal protein gene sequences. Int. J. Syst. Bacteriol. 48:1153-1169.

Marcone, C., A. Ragozzino, and E. Seemuller. 1996. Detection of an elm yellows-related phytoplasma in Eucalyptus trees affected by little-leaf disease in Italy. Plant Dis. 80:669-673.

Maurer, R., E. Seemuller, and W.A. Sinclair. 1993. Genetic relatedness of mycoplasma-like organisms affecting elm, alder, and ash in Europe and North America. Phytopathology 83:971-976.

Orion, D. and A. Frank. 1990. An electron microscopy study of cell wall lysis by Meloidogyne javanica gelatinous matrix. Rev. Nematol. 13:105-107.

Sambrook, J., E.F. Fritsch, and T. Maniatis. 1989. Molecular cloning. A laboratory manual. 2nd ed. Cold Spring Harbor Laboratory, Cold Spring Harbor, N.Y.

Shiomi, T., M. Tanka, S. Uematsu, H. Wakibe, and H. Nakamura. 1999. Statice witches' broom, a Macrosteles striifrons-borne phytoplasmadisease. Ann. Phytopathol. Soc. Japan 65:87-90.

Schneider, B., U.Ahrens, and B.C. Kirkpatrick. 1993. Classification of plant pathogenic mycoplasmalike organisms using restriction site analysis of PCR amplified 16S DNA. J. Gen. Microbiol. 139:519-527.

Tanne, E., L. Kuznetsova, J. Cohen, S. Alexandrov, and A. Gera. 2000. Phytoplasmas as causal agents of celosia diseases in Israel. HortScience 35:103-116.

Valiunas, D.,A.Alminaite, J. Staniulis, R. Jomantiene, and R.E. Davis. 2001. First report of aster yellowsrelated subgroup I-A phytoplasma strains in carrot, phlox, sea-lavender, aconitum, and hyacinth in Lithuania. Plant Dis. 85:804. 